1. MBBS, FCPS (Pak), FRCS (Eng) Classified Orthopaedic Surgeon CMH Malir, Karachi.

Correspondence Address: Dr. Fayyaz Ahmad Orfi Orthopedic Surgeon

$\mathrm{CMH}$ Malir, Karachi

fayyaz_ao@hotmail.com

Article received on: 12/08/2014

Accepted for publication: $14 / 09 / 2015$

Received after proof reading: 00/00/0000

\title{
POP BOOT TRACTION; \\ ITS EFFICACY IN PRE-OP MANAGEMENT OF ACUTE FRACTURES OF UPPER END OF FEMUR
}

\section{Dr. Fayyaz Ahmad Orfi', Dr. Maira Waqas ${ }^{2}$, Dr. Shahid Majeed ${ }^{3}$}

ABSTRACT... Introduction: Fractures of upper end of femur are generally applied some traction pre- peratively. Traditionally either skin or skeletal traction is applied. In this study we applied traction via POP Boot with a T behind ankle in 354 cases of fracture upper end of femur during pre-operative management and the results were compared with those of skin and skeletal traction. Objectives: To see whether effective pre-op traction can be applied via POP Boot in upper femur fractures and what are the complications and cost effectiveness as compared to skin and skeletal traction. Study: In 354 patients POP Boot was applied and $3 \mathrm{~kg}$ tration applied to the injured limb with fracture femur while in 50 cases skin traction and in another 50 cases skeletal traction was applied. Design: It's a randomized prospective double blind study. Settings: Study was carried out in tertiary care hospitals including combined military hospitals of Rawalpindi, Muzaffarabad and Kharian. Period: Study was conducted between the periods of 10 Sep 2003 to 20 Sep 2012 (9 years and 10 days). Methods: All patients have either simple or communited fracture of upper end of femur. All patients were adults and received same amount of analgaesia. $3 \mathrm{~kg}$ traction was applied as standard in all cases. All patients were operated for their fracture femur within 2 to 10 days of applying traction. Results: Results were compared in terms of pain control, reduction achieved, rotational control, and discomfort during application of tration, complications, and cost effectiveness and compared with standard skin and skeletal tractions. Conclusion: POP Boot traction is an easily applied, effective and cost effective way of traction which has very low rate of complications and should be used for pre-op traction in all adult cases with upper femur fracture.

Keywords: $\quad$ Skin Traction, Skeletal Traction. POP (plaster of Paris) Boot Traction, Acute Hip Fracture, AVN (avascular necrosis)

Article Citation: Orfi FA, Waqas M, Majeed S. Pop boot traction; its efficacy in pre-op management of acute fractures of upper end of femur. Professional Med $\mathrm{J}$ 2015;22(12):1624-1628. DOI: 10.17957/TPMJ/15.2609

\section{INTRODUCTION}

Although there are studies which question the beneficial effects of application of traction in acute hip fractures altogether ${ }^{4}$, but application of some sort of traction either skin or skeletal during pre-op phase remains the standard part of management of such fractures. The main advantages of traction application are pain control and assistance in reduction of fracture. Pain control is directly related to the control of movements both axial and rotational at fracture site. ${ }^{7}$

There are claims that pre-op traction application may also reduce the future complication of a vascular necrosis of head of femur in intracapsular fracture neck of femur ${ }^{4}$ but concrete clinical evidence to support this is lacking. Skin traction can cause mechanical shearing, ischemia because of tight bandages, ulceration, blister formation and allergy to adhesive strapping. ${ }^{3}$ Skeletal traction is an invasive procedure in which a metal pin is passed either through tibia or femoral condoyle under local anesthesia. In this study we use a POP-Boot to apply traction to the injured limb and compare it with the traditional skin or skeletal traction.

\section{MATERIAL AND METHOD}

Type of study

Randomized Prospective Study

Types of Participants/Inclusion Criteria:

- Skeletally mature (more than 16 years of age)

- Fully conscious patients (no element of head injury) 
- Having fractures of upper femur (neck or sub trochanteric region)

- Internal fixation done within 2 to 10 days

\section{Exclusion Criteria}

- All patients less than 16 years of age (skeletally immature)

- Patients having ace tabular fractures or pelvic injury

- All patients who remained on traction for more than 10 days (to avoid delayed complications)

- Terminal cases-only to be treated by traction

- Fractures fixed within 24 hours of injury

\section{Types of Intervention}

- 354 patients were applied POP- boot traction with a $\mathrm{T}$ behind ankle

- 50 patients were applied skin traction

- 50 patients were applied skeletal traction under local anesthesia via upper end of tibia or femoral condoyle

\section{Standardization}

- All patients were applied traction on admission day

- $3 \mathrm{~kg}$ traction was applied in all cases as standard

- Inj. Dicloran 75 mg l/M x 08 hourly was given in all cases during first $48 \mathrm{hrs}$ if otherwise not contra-indicated

- Inj. Tramol $50 \mathrm{mg} \mathrm{I/V} \mathrm{x} 08$ hourly was given, if Inj. Dicloran was contra-indicated

- After 48 hrs oral analgesia, Tab. Paracetamol was given as a routine 1-2 tab x 08 hourly

\section{Data Collection}

- Observations were made by the House officers or Medical officers of the ward on daily basis during pre-op period, patients were specially checked for pressure sores in dependant areas, blisters, skin ulceration and allergic reaction.

- All cases were consequently operated and received some sort of internal fixation or partial hip replacement by the same surgeon.

\section{Bias in Study}

- Patients already having skin ulceration or fragile skin or history of skin allergy were not managed by skin traction

- Only short term effects of different tractions were compared and long term outcome were not studied (e.g. AVN etc.)

- Patients operated within the first 24 hours of admission were not included in the study

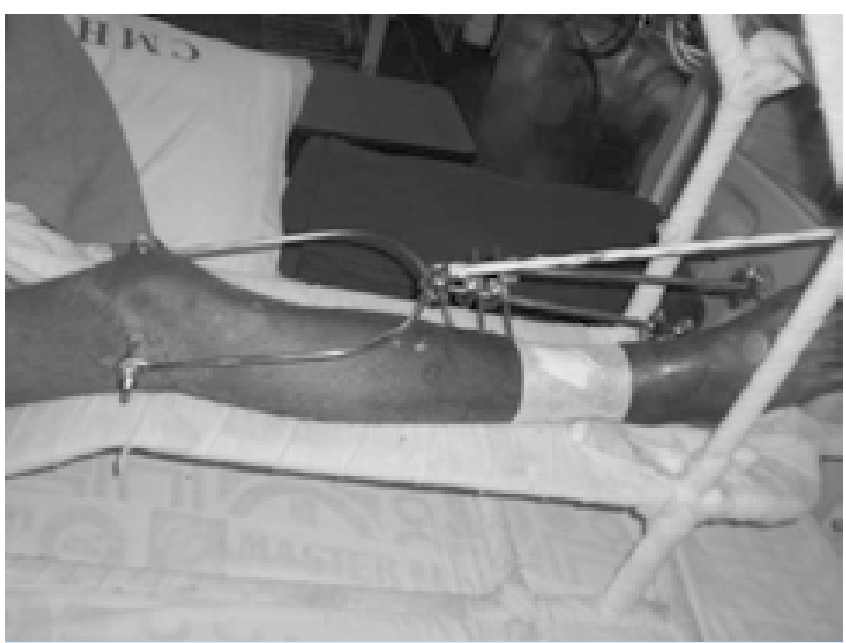

Figure-1. Skeletal Traction

\section{RESULTS}

Pain control was assessed during the first 48 hours as described by the patient in terms of good, fair, little or nil. Good pain control was achieved in $30 \%$ (15) cases of skin traction, $40 \%$ (20) with skeletal traction and $59.8 \%$ (212) with POP-boot traction. Fair in $40 \%$ (20) cases of skin traction, $40 \%(20)$ of skeletal traction and $25 \%$ (177) of boot traction. Little or nil in $30 \%$ cases of skin traction, $20 \%$ of skeletal traction and $15.2 \%$ of POP-boot traction.

Adequacy of reduction was checked in X-ray after 48 hours of traction; good reduction (overlap $<1 \mathrm{~cm}$ ) was achieved in $60 \%(30)$ patients with skin traction, 90\% (45) patients with skeletal traction and $85 \%$ (240) patients with POP- boot traction.

Rotational control was assessed clinically by measuring the external rotation of foot. It was $18 \%$ (09) with skin traction, $70 \%$ (35) with skeletal traction and $90 \%$ (318) with POP-boot traction.

Complications occurred in $20 \%$ of patients with 
skin traction (skin ulceration 03, allergic reaction 05, injury of skin in 02 patients). Rate of pin tract infection was $16 \%(08)$. In one patient it was severe. Bone got exposed after repeated curettage and rotation flap had to be done on the medial aspect of tibia to cover the bone. Complications occurred only in $2.2 \%$ (08) cases with POP-boot traction (mainly skin ulceration).

In skin traction $50 \%$ (25) patients demanded inject able analgesia after 48 hours, 30\% (15) patients with skeletal traction required inject able analgesia while about $20 \%$ (71) with POP- boot traction needed inject able analgesia.

Cost of skin traction is about Rs. 500/-, skeletal traction Rs. 500/- while only about Rs. 150/- with POP-boot traction.

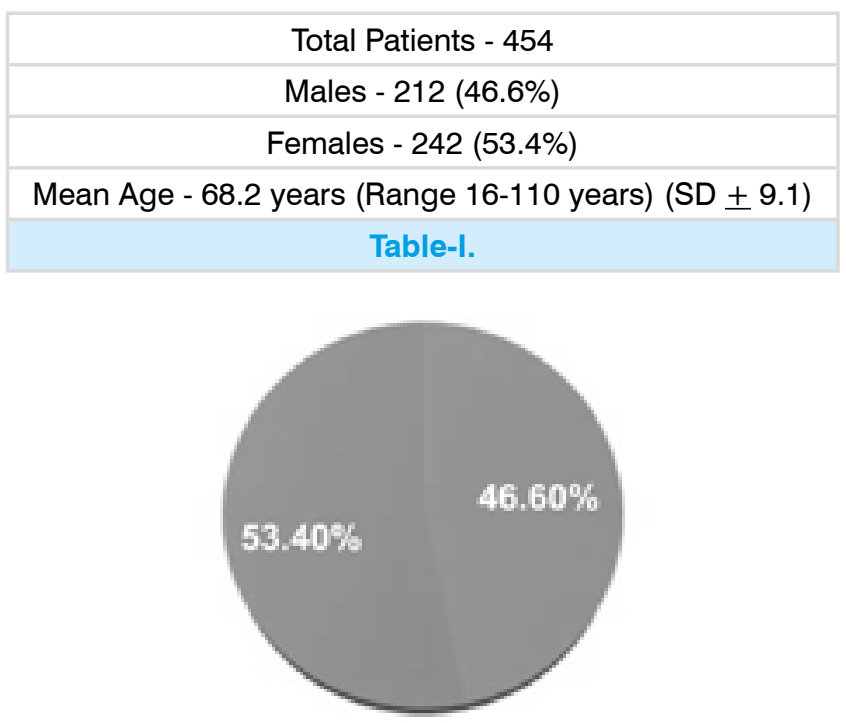

= Male (212) $=$ Female (242)

Fig-2.

\section{DISCUSSION}

Pre-op application of traction to acute hip fractures remains the standard practice all over the world. It helps in pain reduction, assists in fracture reduction, controls rotational element and may reduce the risk of development of AVN of head of Femur in intra-capsular fracture of neck of femur. ${ }^{4}$

\begin{tabular}{|c|c|c|c|}
\hline & $\begin{array}{c}\text { Skin } \\
\text { Traction }\end{array}$ & $\begin{array}{c}\text { Skeletal } \\
\text { Traction }\end{array}$ & $\begin{array}{c}\text { POP Boot } \\
\text { Traction }\end{array}$ \\
\hline $\begin{array}{c}\text { Pain Control } \\
\text { (Good \& Fair) }\end{array}$ & $70 \%(35)$ & $80 \%(40)$ & $84.8 \%(300)$ \\
\hline $\begin{array}{c}\text { Reduction } \\
\text { (Good) }\end{array}$ & $60 \%(30)$ & $90 \%(45)$ & $85 \%(301)$ \\
\hline $\begin{array}{c}\text { Rotational } \\
\text { Control }\end{array}$ & $20 \%(10)$ & $70 \%(35)$ & $90 \%(318)$ \\
\hline Complications & $20 \%(10)$ & $16 \%(08)$ & $2.2 \%(08)$ \\
\hline Analgesia after & $50 \%(25)$ & $30 \%(15)$ & $20 \%(71)$ \\
\hline 48 hrs & $\begin{array}{c}\text { Cost } \\
\text { Co. 500/- }\end{array}$ & Rs.500/- & Rs. 150/- \\
\hline & \multicolumn{2}{|c|}{ Table-II. } & \\
\hline
\end{tabular}

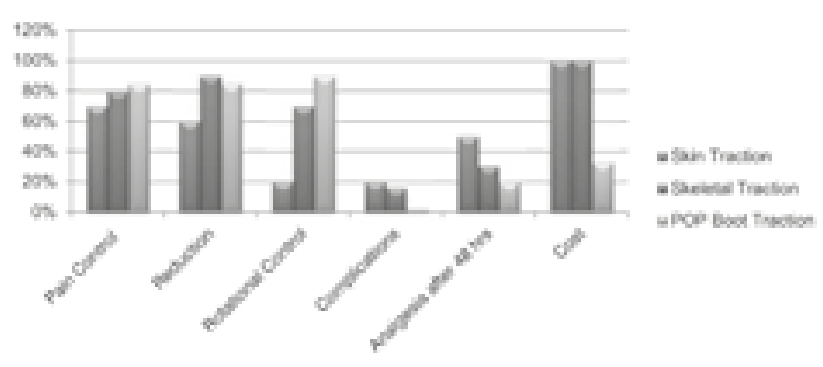

Fig-3.

Although, there are studies which recommend no use of traction during pre-op phase especially if the fracture is fixed within first 48 hours of admission. However, the evidence is not very conclusive. In our setup, because of the work load and paucity of orthopedic surgeons, preop management usually goes beyond 48 hours after admission and application of some sort of traction in acute hip fractures is a routine.

Skin traction cannot be applied in patients with skin disease, ulceration, or allergy to adhesive dressing. ${ }^{9}$ It is ineffective in obese patients as one cannot go beyond $3 \mathrm{~kg}$ of traction because of traction injury risk to the skin. ${ }^{10}$ It does not control the rotational element well and thus pain control is not as good. Moreover, it is cumbersome to apply.

Skeletal traction is quite effective but it needs operative intervention as a metallic pin is passed under local anesthesia either through upper tibia or via femoral condoyle. More weight can be applied in case of heavy patients. Application 
is not pain free and complications specially pin tract infection is not that uncommon- $(18 \%$ in this study). Control of pain is almost comparable to POP-boot traction. However, better reduction can be achieved by applying more weight. In very sick or terminal patients this may be continued as the sole mode of management internal fixation is considered dangerous. ${ }^{12}$

POP-boot traction with a $\mathrm{T}$ behind the ankle is a simple and effective way in controlling the pain and achieving pre-op reduction in patients with acute fractures of upper end of femur. It is easy to apply, cost effective and controls rotational element better than skeletal traction. It is nonoperative and much safer to skin as compared to skin traction. There is no risk of traction injury to skin or allergy to adhesive strapping. It is almost complication free $(2.2 \%)$, minor skin ulcerations.

\section{CONCLUSION}

Whenever traction is applied for fracture of upper end of femur during pre-op management not longer, than 10 days, POP-boot application with a $T$ behind the ankle is an effective and safe way to do that. It is easy to apply and is cost effective, can be applied anywhere by paramedical staff. Controls pain and rotational element better than skin and skeletal traction. There are no risks involved like skin ulcerations, blisters, traction injury to skin, allergy to adhesive strapping and pin tract infection as is the case in routinely applied skin or skeletal traction. The rational use of POP-boot traction is recommended in all cases of acute upper femur fractures during pre-op management. Any long term effects like development of AVN in intra-capsular fracture neck of femur were not studied.

Copyright@ 14 Sep, 2015.

\section{REFERENCES}

1. Anderson $\mathrm{GH}$, Harper WM, Badham J, Goodrich N, Gregg PJ. The effect of preoperative skin traction on pain and morbidity following fracture of the proximal femur, a randomized prospective trial (abs) Journal of Bone and Joint surgery (Br) 1993; 75 Supp 1:42.

2. Anderson GH, Harper WM, Badham J, Goodrich N, Gregg RJ. Preoperative traction for fracture of the proximal femur. Journal of Bone and Joint surgery $(\mathrm{Br})$
1993; 75(5): 794-6.

3. Barns P. Preoperative pillow placement under the injured extremity had better analgesic effects than ski traction for hip fracture. Evidence based Nursing 2002; 5(1): 24.

4. Billsten $M$, Besjakov J, Hyddmark U, Johnal O, Sernbo I. Enquiry in Sweden on the use of traction preoperatively in patients with hip fractures and a radiological studyon the effect of traction on undisplaced cervical hip fractures (abstract). Acta Orthopedica Scandinavica. Supplementum 1996; 270:35.

5. Bank AC, Boonstra O, Van Derwal BCH, Ultee JM, Sclipper IB. Is preoperative traction for proximal femoral fractures beneficial to the patient or comfort to the doctor? European Journal of Trauma 2005; 31(1): 39-43.

6. Draper P. A clinical trial of Hamilton-Russell traction on (a) incidence of pressure sores and (b) preoperative pain in patients with fracture neck of femur. The National Research Register ISS 3; 2000. Oxford.

7. Draper P, Scott F. an evaluation of Hamilton-Russell traction in preoperative management of patients with hip fractures. Clinical Effectiveness in Nursing 1997; 1(4):179-88.

8. Finsen V, Borset M, Buri KGE, Hauke I. Preoperative traction in patients with hip fractures, Injury 1992; 23:242-44.

9. Ghaimat M, Aldweri M, Hijazi A, Shawab Keh J, Obeis $\mathrm{I}$, Magableh $\mathrm{H}$, et al. Preoperative skin traction for fractures of the proximal femur. Journal of Bahrain Medical Society 2005; 17(4): 240-42.

10. Koval KJ. Preoperative skin traction was not useful for hip fractures. Journal of Bone and Joint Surgery(Am.Vol) 2001; 83(2): 303.

11. Parker MJ, Handoll HHG. Preoperative traction for fractures of the proximal femur. Cochrane Database of Systemic Reviews 2003; issue 4.

12. Resch S, Thorngren K G. Preoperative traction foe hip fracture: A randomized comparison between skin and skeletal traction in $\mathbf{7 8}$ patients. Acta Orthopedica Scandinavica Supplementum 1998; 69(3): 277-79.

13. Rosen JE, Chen F S, Hiebert R, Koval K J. Efficacy of preoperative skin traction in hip fracture patients-a prospective randomized study. Journal of Orthopaedic Trauma 2001; 15(2):81-5. 


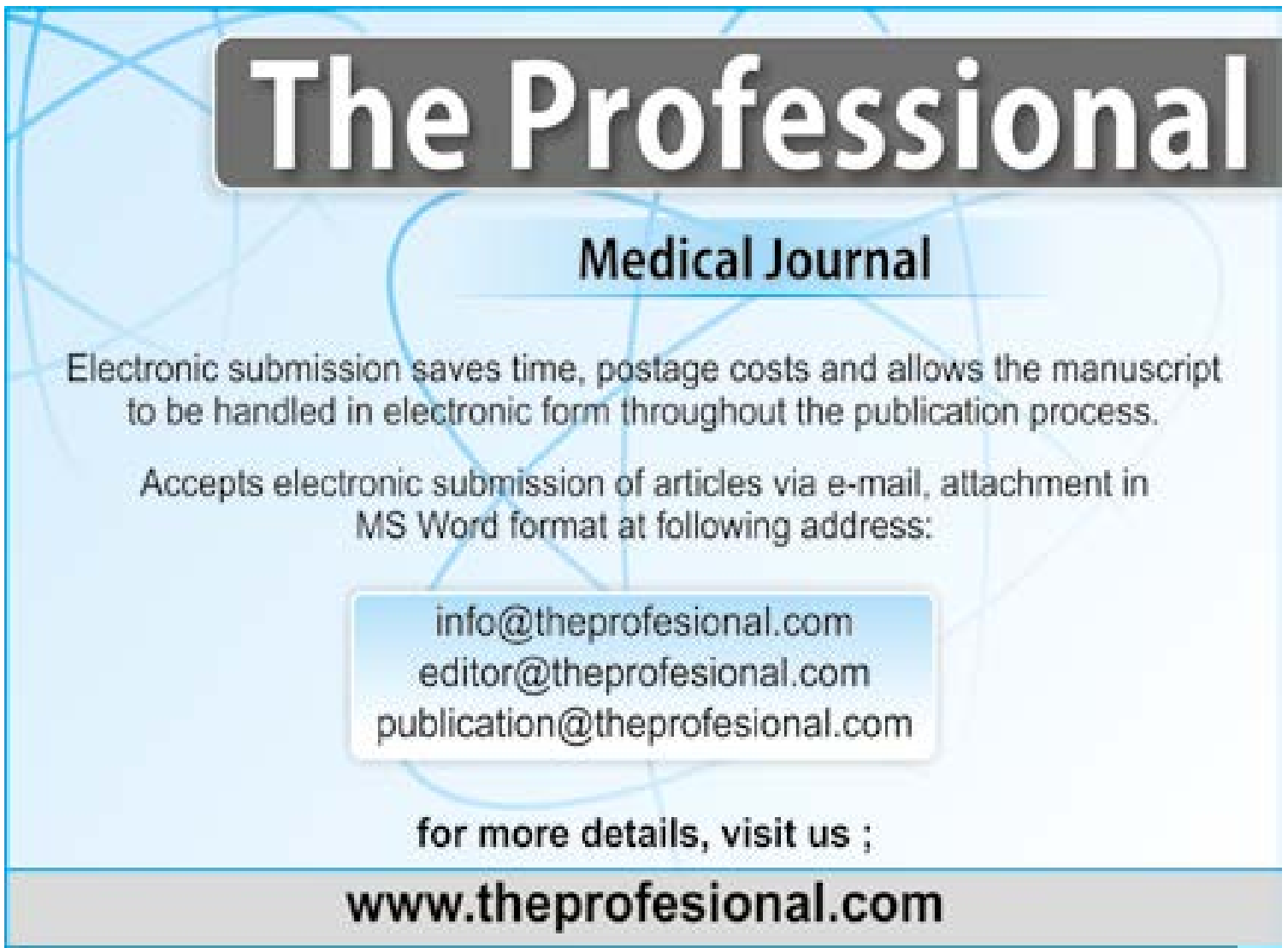

AUTHORSHIP AND CONTRIBUTION DECLARATION

\begin{tabular}{|c|l|}
\hline Sr. \# & Author-s Full Name \\
\hline 1 & Dr. Fayyaz Ahmad Orfi \\
2 & Dr. Maira Waqas \\
3 & Dr. Shahid Majeed \\
\hline
\end{tabular}

Contribution to the paper

Perceine, design \& corrigent the study

Data collection, Statisticas,

Patient care

Analysis, Proof Reading patient care
Author $=\mathbf{s}$ Signature
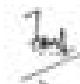

2

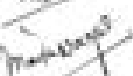

s.t. 5 t. 